\title{
Phytochemical Investigation and Evaluation of Anti-Microbial Activities of Some Indigenous Artemisia Spp. of Ethiopia: Rapid Method of Isolation Artemisinin From Artemisia Annua
}

Seid Mohammed Ebu ( $\nabla$ seid.mohammed@astu.edu.et)

Adama Science and Technology University https://orcid.org/0000-0003-4123-2898

Aman Dekabo

Adama University: Adama Science and Technology University

Tilahun Hailu

Adama University: Adama Science and Technology University

\section{Research Article}

Keywords: Artemisia, anti-bacteria, anti-fungi, artemisinin, sesquiterpene lactone, dibydro-epideoxyartannrrin B

Posted Date: November 11th, 2021

DOI: https://doi.org/10.21203/rs.3.rs-1015085/v1

License: @ (i) This work is licensed under a Creative Commons Attribution 4.0 International License. Read Full License 


\section{Abstract}

Artemisia spp are one of the most important traditional medicinal plants of Ethiopia which are used for the treatment of infection and non-infection health problems. The genus Artemisia (Astraceae) consists of about 500 species worldwide. Previous reports indicated that the different species of Artemisia have a wide array of biological activities including antimalarial, cytotoxic, antihepatotoxic, antibacterial, antifungal and antioxidant activity. In this study, the main aim was to investigate chemical components of Artemisia spp. (A. abyssinica, A. absinthium and A. annua) and evaluate their antimicrobial activities against bacterial strains. The results indicated that the crude extract of these plants were effective against some selected strains of bacterial strains. Here we isolated the well-known antimalarial drug artemisinin (7 mg, 0.004\%) from Artemisia annua leaves using a rapid $n$-hexane fractionation method. The $n$-hexane extract of $A$. abyssinica, ethyl acetate extract of $A$. absinthium and $n$-hexane of $A$. annua showed varying degrees of inhibiting effect against bacterial strains such as Staphylococcus aureus ATCC $25923^{\top}$, Salmonella enteritidis ATCC $13076^{\top}$, Klebsiella pneumoniae ATCC1053 ${ }^{\top}$, boydii ATCC1233 ${ }^{\top}$, Escherichia coli ATCC $25922^{\top}$, hospital acquired Acinetobacter baumannii. The ethyl acetate extract of Artemisia absinthium (A.ab) showed the maximum inhibiting effect (35 $\mathrm{mm}$ ) against $A$. baumannii. The minimum zone of inhibition ( $<3 \mathrm{~mm}$ ) was recorded for test extract of A.ap against Klebsiella pneumoniae ATCC1053 ${ }^{\top}$. Ethyl acetate extract of Artemisia absinthium (A.abe) was more effective against these selected bacterial strains and the zone of inhibition ranged from 5-35 mm. The minimum inhibition zone $\left(8 \mathrm{~mm}\right.$ ) was detected against $S$. typhimurium ATCC $13311^{\top}$ for both A.ac and n-hexane- EtOAc fraction (8:2) of Artemisia abyssinica. The maximum zone of inhibition $(25 \mathrm{~mm}$ ) for fraction (A.ach F4) of Artemisia abyssinica obtained by column chromatography was recorded against S. pyogen ATCC 19615. However, there was no zone of inhibition detected for boydii ATCC1233 ${ }^{\top}$ due to these test extracts. Significant variations $(\mathrm{P}=$ 0.887) were observed between all test extracts of these medicinal plants at $95 \%$ of confidence intervals. There is no zone of inhibition or growth for negative control. But, clear zones of inhibition were detected for positive control due to some standard impregnated disks. Based on our results we recommend that various species of Artemisia seem to have great potential for in-depth investigation for various antimicrobial activities that assists the effort in searching for antimicrobial lead compounds.

\section{Introduction}

The practice of exploiting natural products, the flora and fauna, to alleviate pain and to cure diseases of humans as well as domestic animals is as old as the history of human civilization. Nowadays, the uses of traditional medicinal plants for treatment of some diseases are increasing throughout the world. For instance, in Africa alone, nearly $80 \%$ of the populations uses medicinal plants for their primary health care. Similarly, in countries like China about $30-35 \%$ traditional herbal plants have been employed as a medicinal plants (World Health Organization. Programme on Traditional Medicine 2002). The Artemisia spp. have been also considered as bitter herbs or shrubs in some countries such as Asiatic Steppes,, South Africa, South America and the United States (Rana et al. 2013)

It has been recognized that certain traditional medicinal plants have been employed and act as a first line difference for microbial pathogens. These medicinal plants have been commonly used for treatment of high fever that occurred due to malaria in countries such as Ghana, Mali, Nigeria and Zambia (World Health Organization. Programme on Traditional Medicine 2002). It has been confirmed that the Artimisia spp have contained essential oil that able to inhibit certain pathogenic Bacteria cells such as Staphylococcus aureus, and Staphylococcus epidermidis). Certain fungi species such as Aspergillus niger, Candida albicans, Cryptococcus neoformans, Microsporum canis, and Microsporum gypseum, Trichophyton rubrum, have also been found to be inhibited by essential oil obtained from Artimisia spp in Canada (Lopes-Lutz et al. 2008a)

Recently however, the use of essential oils and other chemical extracts from plant gain great importance due to the increase of their application in pharmaceutical products. They have shown great biological activities such as antimicrobial, antifungal, antiviral and antioxidant activities. In addition some of them have been used in cancer treatment (Abdelwahab et al. 2010; Sylvestre et al. 2006).

Artemisia species, widespread throughout the world, are one of the most popular plants in folk and modern medicine preparations. They are frequently used for the treatment of diseases such as malaria, hepatitis, cancer, inflammation and infections by fungi, bacteria and viruses. Extensive studies of the chemical components of Artemisia species have led to the identification of many bioactive compounds. For instance, Artemisinin is a choice bioactive compound which used as choice of drug for treatment of malaria. It is obtained from Artemisia annua and some microbial sources as a result of genetic engineering. Artemisinin, is a best known bioactive compound for treatment of Trypanosoma brucei brucei with an $\mathrm{IC}_{50}$ value of $35.91 \mu \mathrm{g} / \mathrm{ml}$ and with a selectivity index of 2.44 (Mannan et al. 2010; Nibret and Wink 2010a). These Bioactive compounds may use to heal or treat certain disease. For instance, It has been documented that Artemisia used are frequently utilized for the treatment certain diseases such as cancer, hepatitis, inflammation, infections due to bacteria, fungi, malaria, and viruses (Willcox 2009). The antifungal activity of certain Artemisia species has been reported. For instance, tt has been found that Artemisia extract compounds such as carvone and piperitone are used to inhibit Mucora rouxii and Penicillium citrinum (Chung et al. 2009).

Ethiopia is one of the most important regions in the world for its unique and diverse botanical heritage with diverse topography, vegetable and various climatic conditions (Asefa et al. 2020). It had been also found in different country. For instance, these Artemisia species have been reported in Asia, Europe and North America. They consist of about 500 species. They are small herbs and belonging the Asteraceae family (Bora and Sharma 2011; Willcox 2009).

Artemisia absinthium traditionally known to Ariti in Ethiopia. These Artimisia species is typically identified as an erect, and perennial herb with $30-60 \mathrm{~cm}$ in length (Yineger et al. 2007a). The same Artimisia species have been reported in western Canada (Lopes-Lutz et al. 2008). Artemisia absinthium have been cultivated in some part of Ethiopia for its natural aroma and applied during rituals condition and also referred to adbar (Yineger et al. 2007a). However, the same Artemisia species particularly their essential oil extracts have been employed for inhibiting pathogenic bacterial cells like Staphylococcus strains (Lopes-Lutz et al. 2008). Some study have shown that Artemisia absinthium extracts have been found to use as remedy for the treatment of malaria and is also employed in combination with other herbs for treating wounds of domestic animals (Yineger et al. 2007) 
Artemisia abyssinica (known as 'chikugn' in Ethiopia) is an erect, annual or short-lived perennial herb, $30-60 \mathrm{~cm}$ high. It is quite commonly used in traditional medicine and in rituals. It has been reported for treatment of disease such as rabies, tonsillitis, gonorrhea, cough, syphilis and leprosy. The fresh roots of the same herbs are used to treat epilepsy in domestic animals (Geyid et al. 2005; Yineger et al. 2007b).

Artemisia annua is an erect aromatic annual herb of up to $2 \mathrm{~m}$ in height. It is a common weed over large parts of Eastern Europe and Asia, and has become naturalized in North America. It is cultivated on commercial scale in eastern China, in the Balkans and more recently in India and Africa (Van Wyk 2011). It is an exotic species introduced ten years ago from abroad and currently widely cultivated in southern Ethiopia mainly for its traditional anti-malarial "herbal tea" consumption and as remedy for Hemorrhoid, Asthma and Common cold. It is a source for the production of artemisinin, a sesquiterpene lactone with antimalarial effects against susceptible and multi drug resistant Plasmodium species (Hailu et al. 2013; Nibret and Wink 2010).

The volatile components of Artemisia absinthium, A. abyssinica, A. afra, and A. annua have been characterized using GLC/MS (Nibret and Wink 2010) from extracts of their leaves and aerial parts. Study conducted by Lopes-Lutz et al. (2008) have shown that the extracts of essential oils for these medicinal plants of Artemisia species have been characterized by using GC-MS and GC. It was found that dichloromethane extract of $A$. absinthium contain camphor (38.73\%) major as a major components of compound (Nibret and Wink 2010). Some antioxidant such as beta-carotene or linoleate and 2,2-diphenyl-1-picrylhydrazyl (DPPH) radical have also been reported by using GC-MS and GC for extracts of Artemisia absinthium (Lopes-Lutz et al. 2008). Certain natural products or volatile component such as Octa-3,5-diene-2,7-dione,4,5-dihydroxy ( $A$. abyssinica, 54.95\%), Epoxylinalool ( $A$. afra, 29.10\%) and Deoxyqinghaosu ( $A$. annua, 20.44\%) have been obtained from dichloromethane extract for Artemisia species (Nibret and Wink 2010).

A large number of medicinal plant consents such as essential oils, terpenes, sesquiterpenes and alkaloids have been shown to be found in Artemisia species associated with anti-protozoal, antimicrobial and antifungal activities (Bakhiet and Adam 1995). Nevertheless, a considerable amount of research is still needed to explain the curative effect associated with traditional herbal remedies, to identify simple technology that could produce therapeutic agents at low cost for the alleviation of suffering and infectious disease widespread in the world. The wide utilization of the above three Artemisia species for various diseases of infectious and non-infectious origins triggered us to investigate their chemical compositions and evaluate their in vitro effects against some group of infectious bacteria.

\section{Material And Methods Sample collection}

The samples of Artemisia absinthium which locally known as "Arity" were collected from around Bale Robe, Indato Gasera (Fig. S1a) and A. annua were obtained from Wondogenet (Fig. S1c) research center, respectively. The people living around Robe Bale commonly use Artemisia absinthium (Fig. S1b) against different ailments. Artemisia absinthium were highly available and purchased from different markets in Ethiopia.

Extraction and fractionation of Artimisia abyssinica

The leaves of Artemisia abyssinica (Local name: Ajoo in Afan oromo) (5 g ) were air dried and extracted with n-hexane/Ethyl acetate (8:2) for one day at room temperature which were then filtered and concentrated using rotary evaporator to yield $2 \mathrm{~g}$ blackish oil crude extract. The crude extract $(1 \mathrm{~g})$ was then subjected to column chromatography using increased polarities of the n-hexane/ethyl acetate solvent system and yielded fractions 1-6 (Table 1).

Steam distillation of leaves of Artimisia abyssinica

A $100 \mathrm{~g}$ of leaves of the plant was ground and steam distilled for $3 \mathrm{hrs}$ and the distillate was then poured into a Separatory funnel with $100 \mathrm{ml}$ of chloroform. The organic phase was separated from the aqueous phase by using the Separatory funnel. The organic layer was dried using anhydrous $\mathrm{Na}_{2} \mathrm{SO}_{4}$ and filtered. The oil extracted had been concentrated using Rotary Evaporator and yielded yellowish oil $(0.02 \mathrm{~g})$.

Extraction of leaves of and isolation of compounds from Artimisia annua

Isolation of artemisinin from A. annua leaves

Ground leaves of $A$. annua ( $200 \mathrm{~g})$ were extracted with distilled water $(150 \mathrm{ml})$, while shaking for 8 hrs and filtered using Whatman No. 1 filter paper. The filtrate was then added into a Separatory funnel and fractionated with $150 \mathrm{ml}$ of $\mathrm{n}$-hexane three times. The $\mathrm{n}$-hexane was then concentrated using a rotary evaporator and yielded a white crystal coded as AANH-1 (7 mg, 0.004\%).

Extraction of $A$. abyssinica and A. absinthium leaves

Leaves of $A$. abyssinica $(50 \mathrm{~g})$ and $A$. absinthium $(50 \mathrm{~g})$ were extracted with distilled water $(50 \mathrm{ml})$ by shaking for 8 hrs. The extracts were then filtered using filter paper. The filtrate was then added into a Separatory funnel containing $50 \mathrm{ml}$ of $\mathrm{n}$-hexane each. The organic ( $\mathrm{n}$-hexane) layer was then fractionated from the aqueous layer three times. The $\mathrm{n}$-hexane was then concentrated using a rotary evaporator and yielded white solid (30 mg, $0.06 \%)$ and ( $50 \mathrm{mg}, 0.1 \%)$, respectively. These extracts were then compared with that of n-hexane of $A$. annua (Fig. S1d) using TLC plate, solvent system n-hexane/EtOAc (7:3).

Methanol extraction and isolation of compounds from leaves of A. annua

Methanol extraction of leaves of A. annua 
Fresh leaves of $A$. annua were dried, powdered (Fig. S1d) air dried for a week. A 100 grams of powdered leaves of Artemisia annua macerated using methanol three times and filtered. The extract was then evaporated using a rotary evaporator vacuum at a temperature of $40^{\circ} \mathrm{C}$. Distilled water ( $\left.50 \mathrm{ml}\right)$ was added to the methanol crude extract and partitioned using $50 \mathrm{ml}$-hexane three times using a Separatory funnel. The aqueous layer was then further fractionated using 50 $\mathrm{ml}$ of ethyl acetate three times. Each extract was concentrated using a rotary evaporator at a temp of $40^{\circ} \mathrm{C}$ and yielded $\mathrm{n}$-hexane fraction ( $21 \mathrm{~g}$, $\left.21 \%\right)$ and ethyl acetate fractions $(9 \mathrm{~g}, 9 \%)$.

Purification of $n$-hexane fraction of leaves of A. annua.

The most viscous $n$-hexane extract of the plant was fractionated by column chromatography using silica gel 60 as the stationary phase and a mixture of ethyl acetate-hexane with increasing polarity (gradient elution) as a mobile phase. Fractions 1-3 were obtained using n-hexane as an eluent and fraction 4-7 were collected using n-hexane-EtOAc (97:3) and fraction 8-10 were collected using n-hexane/EtOAc (9:1). Fractions 6 and 7 were found as amorphous compounds after concentrated with a rotary evaporator and showed single spots with the same Rf values with n-hexane-EtOAc (97:3). Then fraction 7 was submitted for NMR analysis. Fraction 6 was (Fig. 4c) stored at $4^{\circ} \mathrm{C}$ and used for antimicrobial activity (antibacterial and fungal) and antimalarial study.

\section{Characterization of isolated compounds from A. annua}

The ${ }^{1} \mathrm{H}$ and ${ }^{13} \mathrm{C}$ NMR were recorded in $\mathrm{CDCl}_{3}$ using the solvent peak as reference (chloroform: $\delta \mathrm{H} 7.26$ and $\delta \mathrm{C} 77.10$. Chemical shift values were reported in $\delta$ (ppm) units, the solvent signals as internal references. ${ }^{1} \mathrm{H},{ }^{13} \mathrm{C}$, and DEPT spectra were obtained on a Bruker UltrashieldTM 400 spectrometer at 400 and 100 $\mathrm{MHz}$, with TMS and solvents as internal standard and values were given in ppm relative to TMS internal standard.

\section{Tested microorganisms and Antimicrobial Activity Assay}

The standard strains used in this study were Klebsiella pneumoniae ATCC170 ${ }^{\top}$, Escherichia coli ATCC 25922 ${ }^{\top}$, Hospital acquired A. baumannii,. Staphylococcus aureus ATCC $25923^{\top}$, Salmonella enteritidisATCC $13076^{\top}$, boydii ATCC $1233^{\top}$, Streptococcus pyogen ATCC $19615^{\top}$ and $S$. typhimurium ATCC $13311^{\top}$ The strains were subcultured and incubated at $37^{\circ} \mathrm{C}$ for $24 \mathrm{~h}$ using Nutrient Broth and was kept refrigerated on Nutrient agar slants for up to 2 weeks. Antibacterial activities test

Disk diffusion method and agar well diffusion were used to detect antimicrobial activities of crude extracts, fractions and essential oils leaves of the plants using a Muller Hinton agar media (Merck, Germany) (Beef extract, $2 \mathrm{~g}$; Acid Hydrolysate of Casein, $17.5 \mathrm{~g}$; starch, $1.5 \mathrm{~g} ; \mathrm{Agar}, 17 \mathrm{~g}$ ).

\section{Disk diffusion method}

Disk diffusion method of antibacterial activities was performed (Bauer et al. 1966). Briefly, Muller Hinton agar media was used as a culture medium. Concentrations of $1-2 \times 10^{8} \mathrm{CFU} / \mathrm{ml}$ of bacterial inoculate were used. McFarland 0.5 was used as standard controls for bacterial inoculum. The media were poured onto $90 \mathrm{~mm}$ diameter petri plates until the thickness of the agar was $4 \mathrm{~mm}$ so that possible problems of diffusion of the tested products could be prevented. A $0.1 \mathrm{ml}$ of each bacterial solution was inoculated and uniformly distributed onto the plates by means of sterile swabs. Plates were allowed to stand for $15 \mathrm{~min}$. At the same time, $6 \mathrm{~mm}$ diameter disks were soaked/ impregnated with the crude extracts, fraction and essential oils of Artemisia spp using different concentrations. The impregnated disks were symmetrically placed onto the medium by using sterile tweezers. One of the disks was soaked with sterile distilled water and used as a negative control. The plates were incubated for $24 \pm 2 \mathrm{~h}$ at $37^{\circ} \mathrm{C}$ under anaerobic conditions. The results were evaluated by measuring the areas with no bacterial growth. These experiments were carried out in triplicates and control cultures were prepared for all the strains.

\section{Agar well diffusion}

Agar well diffusion was also conducted following the methods of (Sz et al. 2016) with some modification. Briefly, about 15-20ml of Mueller Hinton agar was poured on to glass plates of the same size and allowed to solidify. Agar surface of each plate was streaked by a sterile cotton swab with the reference bacterial strain. Agar plates were punched with a sterile cork borer of $6 \mathrm{~mm}$ diameter size using cork borer and al diameter of three agar wells were formed. A $100 \mu \mathrm{l}$ of each sample of diluted crude extracts, fraction and essential oils of the plants were added into respective agar wells. The plates were allowed to standby for $30 \mathrm{~min}$. Different Impregnated antibiotics disks or standard antibiotics were also used as positive control (Table 4). Three of the disks were soaked with sterile distilled water as a negative control. The plates were incubated at $37^{\circ} \mathrm{C}$ for $48 \mathrm{~h}$. The results were recorded by measuring the areas with no bacterial growth. These results were obtained after using the following formula: Inhibition value $=$ Inhibition diameter in $\mathrm{mm}-\mathrm{Disk}$ diameter $(6 \mathrm{~mm}) / 2$. These experiments were carried out in triplicates and control cultures were prepared for these bacterial strains.

\section{Data analysis}

One way ANOVA was used to analyses zone of inhibition due to some test extract obtained from Artemisia spp. Some data was also computed into table and Excel. Post Hoc test was used to determine whether chemosuppression induced by each of the plant extracts was significantly different from the chemosuppression in the positive and negative control group.

\section{Result}

\section{Thin Layer Chromatography Analysis of Artemisia species leaves extracts}

About 10-20 $\mu \mathrm{L}$ sample of test extract compound was spotted on to TLC plate prepared using silica gel and allowed to run in the solvent system consisting of ethyl acetate and n-hexane (3:7) for $40 \mathrm{~min}$ at room temperature. TLC profile and their Rf values for $A$. abyssinica, $A$. absinthium that may contain artemisinin or other sesquiterpene lactones closer in structures with artemisinin were evaluated and required for further analysis. 
In the current study, Artemisinin compound (Fig. 1a) was extracted from the leave part of $A$. annua using ethyl acetate extract, $n$-hexane, and petroleum ether. While extraction, a white crystal $\left(\mathrm{mp} 153-154^{\circ} \mathrm{C}\right)$ designated as AANH-1 was isolated from $\mathrm{n}$-hexane extract of the plant and analyzed by TLC and showed a single spot. The ${ }^{1} \mathrm{H}-\mathrm{NMR}$ of the compound showed highly down field shifted signal $5.88 \mathrm{ppm}$ which appeared as a singlet is due to a presence of proton attached to a carbon containing two oxygen (Table 2, Fig. 2a).

Additionally ${ }^{1} \mathrm{H}$ NMR spectrum indicated the presence of three methyl protons two appeared as doublet and one signal singlet in the compound. The compound has 15 carbon signals ( 3 methyl signals, 4 methylene, 5 methine and 3 quaternary carbons) which indicated the compound is a sesquiterpene (Table 2, Fig. 2b).

\section{Characterization of AAN-7A}

Fraction 7 obtained from $\mathrm{CC}$ of n-hexane extract of $A$. annua as colorless oil. It's TLC showed a single spot indicating the compound is pure. It was then analysed by ${ }^{1} \mathrm{H},{ }^{13} \mathrm{C}$-NMR and DEPT which showed the compound has 15 carbons out of which 3 methyl carbons, 4 methylene carbons, 5 methine carbons and 3 quaternary carbons. ${ }^{13} \mathrm{C}$ and DEPT spectra of the compound showed it has ester carbonyl carbon at 179.5 ppm and olefinic carbon at 142.3 and 121.8 $\mathrm{ppm}$. The compound has also oxygenated quaternary carbon at $83.2 \mathrm{ppm}$.

In this Study, sesquiterpene lactone dibydro-epideoxyartannrrin B. was identified and designed as AAN-7 (Fig. $1 \mathrm{~b}$ ). The ${ }^{1} \mathrm{H}-\mathrm{NMR}$ spectral data of the compound also shown olefinic proton at $5.65 \mathrm{ppm}$, methyl protons at $0.92 \mathrm{ppm}(\mathrm{d}, \mathrm{J}=6.6 \mathrm{~Hz}), 1.15 \mathrm{ppm}(\mathrm{d}, \mathrm{J}=7.1 \mathrm{~Hz})$, and $1.75 \mathrm{ppm}$. Fresh leaves of Artemisia spp (i.e. A. annua) were dried, powdered and cleaned with deionized water and dried at shade for a week. The methanol, petroleum ether and $\mathrm{n}$ hexane were used for extraction.

\section{Antibacterial Activities}

All test extracts of Artemisia abyssinica n-hexane extract, Artemisia absinthium ethyl acetate and $A$. annua n-hexane and petroleum ether showed varying


baumannii, Salmonella enteritidis ATCC $13076^{\top}$, boydii ATCC $1233^{\top}$, and Staphylococcus aureus ATCC $25923^{\top}$. For all bacterial strains against test extract, different zone of inhibition was recorded (Table 4). During our study, the survey showed that the rural community used to treat different infection using these traditional medicinal plants. These infections may be due to bacteria or fungi. Specially, Artemisia abyssinica which is a native medicinal plant to Ethiopia in the area is a well-known traditional medicine for healing of some infections.

Our study showed that test extract of Artemisia annua and Artemisia absinthium have oil. It was proved that these plants are used to produce a considerable amount of essential oil which might be used to inhibit growth of some hospital acquired bacterial pathogens such as hospital acquired $A$. baumannii (Fig. 3a). In this study, the crude extract of Artemisia absinthium ethyl acetate extract (A.ab $)$ showed the maximum inhibiting effect (35mm) (Table-4) and followed by $n$ hexane extract of Artemisia annua (A.ah) against Hospital acquired A. baumannii in which zone of inhibition was 34 mm (Fig. $3 a$ ). The minimum zone of inhibition was recorded for (Table 4) test extract of A.ap.

The minimum inhibition zone (8mm) was detected against $S$. typhimurium ATCC $13311^{\top}$ for both A.ac and EtOAc oils (8:2) of fractionated test extract. The maximum zone of inhibition ( $25 \mathrm{~mm}$ ) for fractionated test extract of Artemisia abyssinica (A.ach F4) was recorded against S. pyogen ATCC 19615 (Fig. 3b). Significant variations $(\mathrm{P}=0.887)$ were observed between all test extracts of these medicinal plants at $95 \%$ of confidence intervals. During this study, the minimum zones of inhibition were detected for the bacterial strains that were sensitive to the test extract of Artemisia spp in the disk diffusion assay. However, the maximum zone of inhibition was detected for the same medicinal plants in the agar well diffusion assay.

In the present study, our finding showed that Hospital acquired A. baumannii is highly sensitive for test extract of A.ah and A.abe with a range of zone of inhibition (15-35mm) in diameter (Fig. 3c). The same bacterial species is highly sensitive for some standard impregnated commercial disks (Fig. 3d). In the current study, A.abe is especially more potent against the staphylococcus aureus (Fig. 3e\&f). A significant variation was observed among A.abe \& A.ah $(P=0.760)$, A.abe \& A.ap ( $P=0.625)$, A.abe \& A.achF4 ( $P=0.582)$, A.abe \& A.achF3 $(P=0.582)$, and A.abe \& AachF5 ( $P=0.399)$, A.abe \& Aach or EtOAc $(P=0.354)$ and A.abe \& AaCh oil $(P=0.554)$

In this study, the maximum zone of inhibition was $19.67 \mathrm{~mm}$ and the minimum inhibition zone was $12 \mathrm{~mm}$ against Escherichia coli ATCC 25922 due to A.ah (Fig. 4a). For A.ach oil, the maximum zone of inhibition was recorded for Escherichia coli ATCC 25922 and followed by A.achF4 which is 15 mm in diameter (Fig. 4b).

The test extract of A.ah, A.ap and A.abe were also used to inhibit the growth of Klebsiella pneumoniae ATCC1053 ${ }^{\top}$ which is a food borne bacterial pathogen. In the present study, the minimum zone of inhibition ( $<3 \mathrm{~mm}$ or range between $<3 \mathrm{~mm}-5 \mathrm{~mm}$ ) due these test extract is recorded for Klebsiella pneumoniae

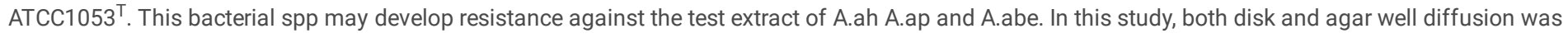
conducted for Shigella boydii ATCC1233 ${ }^{\top}$ However, there was no zone of inhibition detected for Shigella boydii ATCC $1233^{\top}$ (Fig. $4 \mathrm{a}$ ). In this study, the test extract of A.ah and A. abe have synergistic effect on hospital acquired A. baumannii, a hospital acquired pathogenic bacterial spp (Fig. 4b).

In the present study, the distilled water was used as negative control using agar well diffusion and disk diffusion against Salmonella enteritidis ATCC13076 ${ }^{\top}$. Standard impregnated disks were also used as positive control. There is no zone of inhibition or growth for negative control (Fig. S2a). But, a very clear zone of inhibition was detected for positive control due to some standard impregnated disks (Fig. S2b). There was a best synergistic effect for Tetracycline, Ciprofloxacin and Chloramphenicol against Salmonella enteritidis ATCC13076 ${ }^{\top}$. At the same time, the test extract of Artemisia species such as A.ah, A.ap, 
A.ac and A.abe were used against the same bacterial species. A test extract of A.ap has inhibitory effect against Salmonella enteritidis ATCC13076 ${ }^{\top}$ with a very clear zone of inhibition (34 mm) (Fig. S2c). For instance, traditionally the community uses A. abysinthium for treatment of gastric pain. As shown in Fig. 4d, no inhibition effect against Shigella boydii by A.ap. extracts.

\section{Discussion}

Our Samples had been characterized by using NMR. The carbonyl signal at $172.1 \mathrm{ppm}$ indicated the compound has an ester group. A highly down field shifted methyne carbon signal at $105.4 \mathrm{ppm}$ and a quaternary carbon signal at $93.7 \mathrm{ppm}$ indicated the compound is highly oxygenated. The ${ }^{13} \mathrm{C}$-, $\mathrm{DEPT}$, ${ }^{1} \mathrm{H}$ NMR spectral data of the compound was identified by comparison of its ${ }^{1} \mathrm{H},{ }^{13} \mathrm{C}$ NMR spectral data with those reported for artemisinin (Cafferata et al. 2009; Margueritte et al. 2018). Its melting point was also comparable with those previously reported for the compound by $153-154^{\circ} \mathrm{C}(\mathrm{Klayman}$ et al. 1984$)$, 150 $152^{\circ} \mathrm{C}$ (Acton et al. 1993) and $148-151^{\circ} \mathrm{C}$ (Dahnum et al. 2012). There were different methods of extraction and purification for artemisinin. Dahnum et al. (2012) isolated artemisinin using extraction of $A$. annua with methanol while stirring, portion of the methanol extract with n-hexane followed by column chromatography. It has been confirmed that artemisinin can be purified from A. annua L. using (Appalasamy et al. 2014) Pressurized Hot Water, Soxhlet extraction and maceration with method at $60^{\circ} \mathrm{C}$ followed by HPLC (Hao et al. 2002; Sixt and Strube 2017). Tzeng et al. (2007) obtained pure artemisinin by normal column chromatography of ethanol modified $\mathrm{SC}^{-\mathrm{CO}_{2}}$ extractions of whole parts of $A$. annua. The percentage yield of artemisinin (0.004\%) we obtained in this study is lower than those reported $0.016 \%$ by Dahnum et al. (2012), 0.12\% by (ElSohly et al. 2004; ElSohly et al. 2004; ElSohly et al. 1990). Our methods of purification are fastest with less solvent and purification processes and thus economical for production of the antimalarial drug from $A$. annua leaves when compared with previously reported methods. In the current study, the artemisinin compound was obtained by using Separatory funnel. However, Hao with his co-authors (Hao et al. 2002) obtained artemisinin compound from extract of $A$. annua $L$ by using Microwave-assisted extraction and Soxhlet method. The same authors employed chloroform, cyclohexane, ethanol, $n$-hexane petroleum ether, petroleum ether and trichloromethane for artemisinin extraction.

The ${ }^{1} \mathrm{H}$-NMR spectral data of the compound also indicated the presence of protons on olefinic proton at 5.65 ppm, methyl protons at $0.92 \mathrm{ppm}$ ( $\mathrm{d}$, $\mathrm{J}=6.6$ $\mathrm{Hz}), 1.15 \mathrm{ppm}(\mathrm{d}, \mathrm{J}=7.1 \mathrm{~Hz}$ ), and $1.75 \mathrm{ppm}(\mathrm{s})$ appeared as a. Based on the above spectral data the structure of the AAN-7 was identified as a sesquiterpene lactone dibydro-epideoxyartannrrin B. The compound was previously reported from the stem and leaves Artemisia annua (Brown 2004). The ${ }^{1} \mathrm{H}$ and ${ }^{13} \mathrm{C}$ NMR data of AAN-7 was in a good agreement with those reported by Brown (1992). It has been reported that (Foglio et al. 2002) dibydro-epideoxyartannrrin B when administered orally $(100 \mathrm{mg} / \mathrm{kg})$ on the indomethacin ulcer model inhibited the ulcerative lesion index with $\mathrm{ED}_{50}$ values of $55.6 \mathrm{mg} / \mathrm{kg}$ indicating the compound have a relationship with an increase prostaglandin synthesis.

In the present study, artemisinin was obtained from the test extract of A.ap and A.ah.. All test extracts contain certain essential oil. These test extracts may also contain some other aromatic compounds. These Artimisia species extracts were also shown to inhibition effects. These inhibition effects could be due to the presence of artemisinin, sesquiterpene and other aromatic compounds. In line with this study, it has been reported that (Hanscheid and Hardisty 2018) artemisinin that extracted from $A$. annua have shown antimalarial therapy, The same authors stated that microbial cells might be developed resistance against artemisinin compounds if it will be added into the list of choice drugs. Similarly in our study, no inhibition was observed for Shigella boydii ATCC1233 ${ }^{\top}$ suggesting that this pathogenic bacterial strain may developed resistance toward $A$. annua extracts that predicted to be among artemisinin compound. It was found that the essential oils derived from $A$. absinthium were extracted using microwave assisted process, distillation in water and direct steam distillation methods. These extracts of Artimisia species were shown for their relative toxicity against ascaricides and spider mite, Tetranychus urticae (Chiasson et al. 2001). Study were shown that a sesquiterpene (C15H24) compound that were derived from Artemisia absinthium by using present direct steam distillation (DSD) contained essential oil after the Chromatographic analysis had been performed. These oil have shown lethal effect against adult Tetranychus urticae (Chiasson et al. 2001).

Certain total phenolic content have been detected for $A$. absinthium leaves extracts. This extraction was determined by using the Folin-Ciocalteu (FC) method. These phenolic compounds were included such as benzoic acid, Catechins, flavonols, hydroxycinnamic acids, hydroxybenzoic acids, and Gallic acid (Carvalho et al. 2011). The same authors predicted that these phenolic compounds were used as antioxidants. A reversed-phase high-performance liquid chromatography method (RP-HPLC) coupled with diode-array detection (DAD) and electrospray ionization mass spectrometry (ESI/MS) analysis have shown that certain phenolic compound such as flavonoids (O- and C-glycosylated) and hydroxycinnamic acids derivatives were detected for Artemisia argentea. These phenolic compounds are extracted by using methanol and measured by the Folin-Ciocalteu method (Gouveia-Figueira and Castilho 2011). These authors added that these phenolic compounds have antioxidant capacity. Similar results were observed with other species of Artemisia. Carvalho et al. (2011) isolated both phenolic content and flavonoid compounds from Artemisia species. These compounds are determined by using Folin-Ciocalteau's reagent and methanolic $\mathrm{AlCl}_{3} \cdot 6 \mathrm{H}_{2} \mathrm{O}$, respectively (Carvalho et al. 2011). Similarly, study has shown that the phenolic compounds have been separated by using HPLC method when the Artemisia argentea extracts had been performed by using alcoholic methods of extraction (Gouveia-Figueira and Castilho 2011). For instance, the alcoholic extract of Artemisia argentea was shown to contain a $152.8 \mathrm{mg} 100 \mathrm{~g} \mathrm{DW}-1$ total phenolic content and a $109.20 \mathrm{mg} 100 \mathrm{~g}$ DW-1 flavonoid content i for a given plant material (Carvalho et al. 2011). The phenolic compounds are the dominant antioxidants that show scavenging efficiency due to the presence of free radical compounds which is a reactive oxygen species. These free radicals are commonly reported for diversity of plant species (Prior et al. 2000). For instance, (Chialva et al. 1983) studied that about 19 samples of $A$. absinthium these collected from France, Romania, Siberia and Italy, found to contain free radicals compounds.

Artemisinin has been identified as the anti-malarial principle of the plant. The artemisinin derivatives are nowadays established as anti-malarial drugs with activity towards drug-resistant Plasmodium infections (Klayman 1993). Other natural products may be existed within these Artemisia species in addition to artemisinin compound that detected for specifically Artemisia annua. The presence of natural antioxidants such as alkaloid, flavonoids, phenolic compounds, and terpenes in the aerial parts of A. abysssinica party elaborates the observed effects of plant extract (Taramelli et al. 1999) which is a similar finding to our 
suggestion. Other compound with $\mathrm{tR}=5.0 \mathrm{~min}$ had been identified as 5-0-caffeoylquinic acid Artemisia argentea (Gouveia-Figueira and Castilho 2011). The same authors reported catechins, ferulic and caffeic acid from $A$. argentea and other six related species.

It has been reported that certain chemical components of the essential oil (91-97.1\%) were predicted for $A$. annua. These essential oil components were found to be varying from $0.3-0.7 \%$ during the growth period. The major compositions were identified as borneol (7.5\%), camphor (22.8-42.6\%), $\beta$ caryophyllene (2-9.2\%), 1,8-cineole (3.7-8.4\%), (E)- $\beta$-farnese (1.3-8.5\%), and germacrene D (0.5-7.3\%). Meanwhile, other chemical components such as 1epi-cubenol (0.7-5.2\%). linalool (0.1-11.9\%), $\beta$-pinene (6.5\%), sabinene (8.2\%), and $\beta$-thujone (9.8\%) were identified from an extract of $A$. annua. These chemical compositions were characterized by using two-dimensional GC time-of-flight mass spectrometry (MS) (Abad et al. 2012; Ma et al. 2007; Padalia et al. 2011). After GC-MS and GC analysis had been performed, major components of essential oils such as myrcene, trans-thujone and trans-sabinyl acetate with 10.8, 10.1 and $26.4 \%$. percentage yield were obtained from $A$ absinthium, respectively (Lopes-Lutz et al. 2008). These essential oils showed moderate inhibitory effects against certain microbial cells such as Candida albicans and Staphylococcus aureus. However, the same essential oils were shown weak activities against Escherichia coli, Proteus vulgaris, and Salmonella typhimurium (Abad et al. 2012; Ma et al. 2007; Padalia et al. 2011). These discrepancies in terms of degree of inhibition effect could be due to variation of chemical composition found in these essential oils.

Lopes-Lutz et al. (2008) investigated the chemical composition and antimicrobial activity of essential oil isolated from aerial parts of $A$. absinthium, $A$. biennis, A. cana, A. dracunculus, A. frigida, Artemisia longifolia Nutt. and A. ludoviciana using GC/MS. The same authors confirmed that Artemisia oils had inhibitory effects on the growth of some pathogenic bacteria and fungi. These pathogens are Escherichia coli, Aspergillus niger, Candida albicans, Cryptococcus neoformans, Fonsecaea pedrosol. Microsporum canis, Microsporum gypseum, Staphylococcus aureus, Staphylococcus epidermidis, and Trichophyton rubrum (Lopes-Lutz et al. 2008).Certain fungi disease may be targeted due to some natural products these available within part of Artimisia species. In agreement with this prediction, the dried leaves of Artemisia annua (Jiao et al. 2018) have been shown to be effective against avian coccidiosis which is a fungi disease. These natural products may be existed within leave or root parts of Artimisia species. For instance, in the current study the maximum inhibition zone were detected for ethyl acetate extract using dried and powdered $A$. annua leave part, a similar finding to (Jiao et al. 2018 ). The same authors stated that Artemisinin and Artemisia annua leaves alleviate Eimeria tenella infection by facilitating apoptosis of host cells and suppressing inflammatory response.

Some unidentified bioactive compound may be used to damage certain structure of bacterial cells. Test extract of Artemisia absinthium ethyl acetate extract (A.abe) was more effective against these selected bacterial strains and their zone of inhibition was ranged from 5-35mm. It was found that the whole part of Artemisia absinthium ethylacetate and chloroform extracts used to inhibit test microorganisms such as Staphylococcus aureus ATCC $25923^{\top}$, Pseudomonas fluorescens, Bacillus brevis FMC and Bacillus megaterium DSM with 8-16 mm/20ml inhibition zone (Erdogrul 2002) which is strongly in agreement with our current results.

The essential oil of one of $A$. absinthium, also showed antibacterial activity against commonly known pathogens like Escherichia coli, Salmonella enteritidis, Pseudomonas aeruginosa, Klebsiella pneumoniae and Staphylococcus aureus (Blagojević et al. 2006). In agreement with this finding, an ethyl acetate oil extract of Artemisia absinthium (A.ab $\mathrm{e}_{\mathrm{e}}$ ) tends to show the maximum inhibiting effect $(35 \mathrm{~mm})$ against Hospital acquired $A$. baumannii. This extract might have contained inhibiting bioactive compound that able to target this pathogenic strain. In line with this study, it was stated that the GC/MS used to show the chemical composition and its antimicrobial activity of essential oil extracted from aerial parts of $A$. absinthium, A. cana, A. biennis, A. dracunculus, A. frigida, Artemisia longifolia Nutt, and A. ludoviciana of wild sages from western Canada (Lopes-Lutz et al. 2008). The same authors briefly reported that Artemisia oils able to inhibit growth of pathogenic bacteria such as Escherichia coli, Staphylococcus aureus and Staphylococcus epidermidis.

Fungi species such as Candida albicans and Cryptococcus neoformans were similarly inhibited by extract oil of Artemisia). Aspergillus niger, Fonsecaea pedrosol Microsporum canis, Microsporum gypseum, and Trichophyton rubrum are well known dermatophytes that were inhibited by Artemisia oils (LopesLutz et al. 2008). It was found that the $A$. absinthium essential oil contained component such as $\beta$-thujone (10.1\%), myrcene (10.8\%), and trans-sabinyl acetate (26.4\%). A. biennis extract oil contains the acetylenes (Z), (E)-en-yn-dicycloethers (11\%), cis- $\beta$-ocimene (34.7\%), and trans- $\beta$-farnesene (40\%). $A$. dracunculus oil contained methyl chavicol which is predominant phenylpropanoids and methyleugeno (16.2\%) (Abad et al. 2012b).

It has been reported that water, methanol, ethanol, or acetone extracts of artemisinin which derived from Artemisia annua L. have ability for anti-inflammatory, antioxidant and antimicrobial. The acetone extract is the most candidate of inhibitory effect on lipopolysaccharide-induced nitric oxide (NO), prostaglandin E2 (PGE2), and proinflammatory cytokine (IL-1 $\beta$, IL-6, and IL-10) production. However, the ethanol extract have the best antioxidant activity due to its highest free radical scavenging activity $(91.0 \pm 3.2 \%)$, similar to a -tocopherol (99.9\%) (Kim et al. 2015).

The Methanol extract of the Artemisia vulgaris showed the highest antioxidant and antibacterial properties when compared to the essential oil of the same plants. It has also been stated that the artemisinin compound the ability of inhibitory effect against actinomycete mcomitans, Aggregatibacter,

Fusobacterium nucleatum subsp. animalis, Fusobacterium nucleatum subsp. polymorphum, periodontopathic and Prevotella intermedia microorganisms. For instance, methanol extract used to inhibit F. nucleatum subsp. Polymorphum and Prevotella intermedia which is similar with the current finding (Kim et al. 2015). Johnson et al. (2013) further stated that the methanol solutions of the extracts were found to have a broad spectrum activity against all the microorganisms tested. In the present study, the maximum zone of inhibition for Staphylococcus aureus ATCC 25923 (Fig. 3) was $20.33 \mathrm{~mm}$ and $20 \mathrm{~mm}$ in diameter (Table 4\&5) due to A.abe and A.ach F4, respectively which is more potent than the findings of Johnson et al. (2013).

The interaction in the oil constituents was resulted in synergy effect on microbial spp. except for Salmonella typhi and Escherichia coli ATCC 25922 with zone diameter of $6 \mathrm{~mm}$ each (Johnson et al. 2013). The same author further stated that a minimum zone diameter (6mm) observed for Salmonella typhi and Escherichia coli strains. However, the maximum zone of inhibition were recorded for Candida albicans and Candida albicans ATCC 90028 (30 mm) strains when Tangerine oil extract had been used (Johnson et al. 2013). 
In line with this study, (Patil et al. 2011) extracted and obtained physiologically active composition in pure or mixture form from some Artemisia sp. such as $A$. dracunculus, A. herba-alba, A. judaica, A. vulgaris, A. abysinica, A. absynthicum, A. afra, A. cannariensis, A. pallens, A. annua, A. abrotanum, A. ludoviciana, and $A$. capillaris or $A$. scoparia (Patil et al. 2011). Moreover, the same author stated these plants used to prevent or treat (pre) diabetes and associated accompanying diseases or secondary diseases. The best zone of inhibition for essential oil of Boswellia papyrifera for bacteria was obtained for Salmonella enterica CIP 105150 (40 mm), Bacillus cereus LMG 13569 (39 mm), Enterococcus faecalis CIP 103907 (39 mm), Shigella dysenteria CIP 5451 (31 mm), Staphylococcus camorum LMG 13567 (30 mm). The other strains had sensitivities between 15-28 mm. The best zone of inhibition of methanol extract of Boswellia papyrifera were obtained for Enterococcus faecalis CIP 103907 (30 mm), Bacillus cereus LMG 13569 (27 mm). The other strains had sensitivities between 6-24 mm (Abdoul-latif et al. 2012).

The bacteria are resistant to test extract of all Artemisia spp. This might be due inappropriate concentration of test extract. Or the test extract might be inefficient to inhibit this bacterial strain. Abdoul-latif et al. (2012) is also stated that Proteus mirabilis CIP 104588 is resistant to the methanol extracts of Boswellia sacra and Boswellia papyrifera while Shigella dysenteria CIP 5451 is resistant to the methanol extract of Boswellia sacra only. Essential oils of Boswellia sacra and Boswellia papyrifera present an antimicrobial activity stronger than the ticarcycline for Enterococcus faecalis $\mathrm{CIP}^{103907^{\top}}$, Escherichia coli CIP $105182^{\top}$, Shigella dysenteria CIP $5451^{\top}$, Staphylococcus camorum LMG $13567^{\top}$, Pseudomonas aeruginosa and Proteus mirabilis CIP $104588^{\top}$ (only for essential oil of Boswellia sacra). The methanol extracts of Boswellia sacra and Boswellia papyrifera have an antimicrobial activity weaker than the ticarcycline except for Escherichia coli CIP 105182 (Abdoul-latif et al. 2012).

In Afro-Asian countries, many species of Artemisia such as A. abyssinica are used in folk medicine as anthelmintics, antispasmodics, antirheumatics and antibacterial agents due to the presence of the presence of certain natural products such as alkaloids, anthraquinones, flavonoids, sterols, tannins, and volatile oils (Adam et al. 2000). Certain essential oils are also reported from Artemisia asiatica Nakai. These essential oils have shown antibacterial and antifungal effects. They include such as 1,8-cineole, selin-11-en-4alpha-ol and monoterpene alcohols fraction. These essential oils have been found to be effective against Bacillus subtilis, Aspergillus fumigatus, Candida albicans, Escherichia coli, Rhodotorula rubra, Pseudomonas aeruginosa and Staphylococcus aureus. The monoterpene alcohols have specifically shown inhibiting effects against certain bacterial cells (Kalemba et al. 2002). In our study, it was confirmed that Artemisia annua have shown antimicrobial properties. It could be due to the presence of secondary metabolites, a work similar to Appalasamy et al. (2014). In agreement with our finding, (Appalasamy et al. 2014) extracted the main bioactive compound which is artemisinin from $A$. annua $\mathrm{L}$. that collected from Malaysia. due to the tropical hot climate, $A$. annua could not be planted for production of artemisinin, the main bioactive compound. The same authors found out that the $A$. annua L. leave extract is able to inhibit certain gram-negative and Gram-positive and Gram-negative bacteria. However, the leaf extract of $A$. annua $\mathrm{L}$ is unable to inhibit Candida albicans (Appalasamy et al. 2014). It was found that aerial parts of $A$. abyssinica and $A$. herba-alba extracts are also employed and shown in molluscicides effect. It was suggested that the molluscicides are due to the presence of sesquiterpene lactones and terpenoid compounds in these medicinal plants (Segal 1985; Watt and Breyer-Brandwijk 1962). However, in our study, inhibition activities were detected for Artemisia annua petroleum ether extract, Artemisia absinthium ethyl acetate extract and $A$. abyssinica were detected against certain medically important bacterial pathogens such as E. Coli ATCC $25922^{\top}$, Hospital acquired A. baumannii, Salmonella enteritidis ATCC13076 ${ }^{\top}$ and S. aureus ATCC $25923^{\top}$. This could be due to the presence of Artemisinin and other sesquiterpene compounds. These compounds may target certain bacterial structures such as cell wall, cell membrane, genetic material or ribosome that are used for protein synthesis. It has been observed that the extract compounds obtained from Artemisia species have shown insecticidal and repellent activities (Malik and Mujtaba Naqvi 1984).

In the current study, these Artemisia absinthium, a traditionally known as Ariti have been shown inhibitory effects against certain pathogenic bacterial cells such as E. Coli ATCC $25922^{\top}$, Hospital acquired A. baumannii, Klebsiella pneumoniae ATCC1053' , Salmonella enteritidis ATCC13076 ${ }^{\top}$ and S. aureus ATCC $25923^{\top}$. Mostly, in Ethiopia these Artemisia species are employed for ritual during solemn ceremonies.

The Artemisia abyssinica have shown inhibitory effects against certain bacterial pathogens. These Artemisia species are traditiona/ referred to as Ajo. It is highly grown some highland environments. These plants are commonly employed for house cleaning rather than as traditional medicinal plants. It has repellent and pungent odors. The same Artemisia species traditionally known as Ather in Saudi Arabia (Adam et al. 2000), where these plants are abundantly grown. The same authors classified Artemisia abyssinica under the family of Asteraceae. Furthermore, it was stated that $A$. abyssinica have shown certain effects on the growth, haematological (treatment of the blood) and organ pathology in rats at a low concentration (Adam et al. 2000). The test extract of Artemisia species such as A.ah, A.ap A.ac and A.abe were used against certain bacterial species. A test extract of A.ap has inhibitory effect against Salmonella enteritidis with a very clear zone of inhibition (34 mm) (Fig. S2c). It was found that leaves and aerial parts of extract for Artemisia species such as Artemisia absinthium, A. abyssinica, A. afra, and A. annua have been found to be effective against Trypanosoma brucei brucei with in Ethiopia (Nibret and Wink 2010b)

\section{Declarations}

\section{Acknowledgments}

This research was funded by Adama Science and Technology University. We also thank Dr. Yadessa Melaku for his assistance in the project.

Thanks to all laboratory students who were helped during sample collection.

\section{Authors' contributions}

All authors have contributed to this study. The chemistry parts have been addressed by Professor Aman, The Antimicrobial part addressed by Dr. Seid Mohammed and The plant sample collection, and botanically identification had been performed by Mr, Tilahun Hailu. All authors read and equally approved 
the final manuscript.

\section{Funding}

This work has been supported financially by Adama Science and Technology University

\section{Declarations}

Not applicable

\section{Availability of data and materials}

All discussed data have been included into this manuscript

\section{Ethics approval and consent to participate}

The current study protocol was approved by the Adama Science and Technology University, Ethiopia.

\section{Consent for publication}

Not applicable.

\section{Competing interests}

The authors declare no conflict of interest among each other's. The Adama Science and Technology University who finds this project had no role in the design of the proposal development, the study design, sample collection, data analyses, and date interpretation; in the writing of this manuscript, or in the decision to publish the current of these results.

\section{References}

1. Abad MJ, Bedoya LM, Apaza L, Bermejo P, The Artemisia L, Genus A Review of Bioactive Essential Oils. Molecules [Internet]. $2012 a$ Mar 2 [cited 2020 Dec 22];17(3):2542-66. Available from: https://www.ncbi.nlm.nih.gov/pmc/articles/PMC6268508/

2. Abad MJ, Bedoya LM, Apaza L, Bermejo P, The Artemisia L, Genus A Review of Bioactive Essential Oils. Molecules [Internet]. $2012 b$ Mar [cited 2019 Nov 20];17(3):2542-66. Available from: https://www.mdpi.com/1420-3049/17/3/2542

3. Abdelwahab SI, Zaman FQ, Mariod AA, Yaacob M, Abdelmageed AHA, Khamis S (2010 Dec) Chemical composition, antioxidant and antibacterial properties of the essential oils of Etlingera elatior and Cinnamomum pubescens Kochummen. J Sci Food Agric 90(15):2682-8

4. Abdoul-latif FM, Bayili RG, Obame L-C, Bassolé IHN, Dicko MH Comparison of phenolic compounds and antioxidant capacities of traditional sorghum beers with other alcoholic beverages. Afr. J. Biotechnol. [Internet]. 2012 [cited 2021 Oct 19];11(81):14671-8. Available from:

https://www.ajol.info/index.php/ajb/article/view/129435

5. Acton PD, Alexander G, Allison J, Allport PP, Anderson KJ, Arcelli S A study of differences between quark and gluon jets using vertex tagging of quark jets. Z. Für Phys. C Part. Fields [Internet]. 1993 Sep 1 [cited 2021 Oct 18];58(3):387-403. Available from: https://doi.org/10.1007/BF01557696

6. Adam S, Al-Qarawi A, Elhag E (2000 Aug) Effects of various levels of dietary Artemisia abyssinica leaves on rats. Lab Anim 1:34:307-312

7. Appalasamy S, Lo KY, Ch'ng SJ, Nornadia K, Othman AS, Chan L-K (2014) Antimicrobial Activity of Artemisinin and Precursor Derived from In Vitro Plantlets of Artemisia annua L. BioMed Res. Int. [Internet]. [cited 2021 Oct 20];2014:215872. Available from:

https://www.ncbi.nlm.nih.gov/pmc/articles/PMC3915762/

8. Asefa M, Cao M, He Y, Mekonnen E, Song X, Yang J Ethiopian vegetation types, climate and topography. Plant Divers. [Internet]. 2020 Aug 1 [cited 2021 Oct 18];42(4):302-11. Available from: https://www.sciencedirect.com/science/article/pii/S2468265920300378

9. Bakhiet AO, Adam SE Therapeutic utility, constituents and toxicity of some medicinal plants: a review. Vet. Hum. Toxicol. [Internet]. 1995 Jun [cited 2019 Jul 3];37(3):255-8. Available from: http://europepmc.org/abstract/med/7571361

10. Bauer AW, Kirby WM, Sherris JC, Turck M (1966 Apr) Antibiotic susceptibility testing by a standardized single disk method. Am J Clin Pathol 45(4):493-6

11. Blagojević P, Radulović N, Palić R, Stojanović G Chemical composition of the essential oils of serbian wild-growing Artemisia absinthium and Artemisia vulgaris.J. Agric. Food Chem. 2006 Jun28;54(13):4780-9

12. Bora KS, Sharma A (2011 Jan) The genus Artemisia: a comprehensive review. Pharm Biol 49(1):101-109

13. Brown GD (2004) Two New Compounds from Artemisia annua [Internet]. ACS Publ. American Chemical Society; [cited 2021 Oct 18]. Available from: https://pubs.acs.org/doi/pdf/10.1021/np50090a006

14. Cafferata L, René J, Rimada R, Gatti W (2009) Isolation, characterization and quantification of artemisinin by NMR from Argentinean Artemisia annua L. Bol. Latinoam. Caribe Plantas Med. Aromáticas. Jul 1;8

15. Carvalho I, Cavaco T, Brodelius M Phenolic composition and antioxidant capacity of six Artemisia species.Ind. Crops Prod. 2011 Dec4;33:382-8

16. Chialva F, Liddle PAP, Doglia G Chemotaxonomy of wormwood (Artemisia absinthum L.). Z. Für Lebensm.-Unters. Forsch. [Internet]. 1983 Sep 1 [cited 2021 Oct 18];176(5):363-6. Available from: https://doi.org/10.1007/BF01057728 
17. Chiasson H, Bélanger A, Bostanian N, Vincent C, Poliquin A (2001 Feb) Acaricidal properties of Artemisia absinthium and Tanacetum vulgare (Asteraceae) essential oils obtained by three methods of extraction. J Econ Entomol 94(1):167-171

18. Chung EY, Byun YH, Shin EJ, Chung HS, Lee YH, Shin S (2009 Dec) Antibacterial effects of vulgarone B from Artemisia iwayomogialone and in combination with oxacillin. Arch Pharm Res 32(12):1711-9

19. Dahnum D, Abimanyu H, Senjaya A (2012) Isolation of Artemisinin as Antimalarial Drugs from Artemisia annua L. Cultivated in Indonesia. Int J Od Basic Sci Citeseer 12:90-95

20. EISohly H, Croom E, El-Feraly F, El-Sherei M (2004) A Large-Scale Extraction Technique of Artemisinin from Artemisia annua.J. Nat. Prod. - J NAT PROD. Jul 1;53.

21. ElSohly HN, Croom EM, El-Feraly FS, El-Sherei MM A Large-Scale Extraction Technique of Artemisinin from Artemisia annua. J. Nat. Prod. [Internet]. 1990 Nov [cited 2021 Oct 18];53(6):1560-4. Available from: https://pubs.acs.org/doi/abs/10.1021/np50072a026

22. Erdogrul ÖT (2002) Antibacterial Activities of Some Plant Extracts Used in Folk Medicine. Pharm. Biol. [Internet]. Jan [cited 2019 Nov 21];40(4):269-73. Available from: https://www.tandfonline.com/doi/full/10.1076/phbi.40.4.269.8474

23. Foglio MA, Dias PC, Antônio MA, Possenti A, Rodrigues RAF, da Silva EF et al (2002 Jun) Antiulcerogenic activity of some sesquiterpene lactones isolated from Artemisia annua. Planta Med 68(6):515-8

24. Geyid A, Abebe D, Debella A, Makonnen Z, Aberra F, Teka F et al (2005) Screening of some medicinal plants of Ethiopia for their anti-microbial properties and chemical profiles. J. Ethnopharmacol. Mar 21;97(3):421-7

25. Gouveia-Figueira S, Castilho P Antioxidant potential of Artemisia argentea L'Hér alcoholic extract and its relation with the phenolic composition.Food Res. Int. 2011 Jul1;44:1620-31

26. Hailu TT, Foit L, Bardwell JCA (2013) In Vivo Detection and Quantification of Chemicals that Enhance Protein Stability. Anal. Biochem. [Internet]. Mar 1 [cited 2019 Jul 3];434(1):181-6. Available from: https://www.ncbi.nlm.nih.gov/pmc/articles/PMC3670414/

27. Hanscheid T, Hardisty DW (2018 Aug) How "resistant" is artemisinin resistant malaria? - The risks of ambiguity using the term "resistant" malaria. Travel Med Infect Dis 24:23-24

28. Hao J, Han W, Huang S, Xue B, Deng X (2002) Microwave-assisted extraction of artemisinin from Artemisia annua L. Sep. Purif. Technol. [Internet]. Sep 1 [cited 2021 Oct 18];28(3):191-6. Available from: https://www.sciencedirect.com/science/article/pii/S1383586602000436

29. Jiao J, Yang Y, Liu M, Li J, Cui Y, Yin S et al Artemisinin and Artemisia annua leaves alleviate Eimeria tenella infection by facilitating apoptosis of host cells and suppressing inflammatory response.Vet. Parasitol. 2018 Apr30;254:172-7

30. Johnson 00, Ayoola GA, Adenipekun T (2013) Antimicrobial activity and the chemical composition of the volatile oil blend from Allium sativum (garlic clove) and Citrus reticulata (tangerine fruit). Int. J. Pharm. Sci. Drug Res. [Internet]. a Oct 1 [cited 2021 Oct 18];187-93. Available from:

http://www.ijpsdr.com/index.php/ijpsdr/article/view/284

31. Kalemba D, Kusewicz D, Swiader K (2002 May) Antimicrobial properties of the essential oil of Artemisia asiatica Nakai. Phytother Res PTR 16(3):288291

32. Kim S, Lee H, Lee S, Yoon Y, Choi K-H Antimicrobial Action of Oleanolic Acid on Listeria monocytogenes, Enterococcus faecium, and Enterococcus faecalis. PLOS ONE [Internet]. Public Library of Science; 2015 Mar 10 [cited 2021 Oct 18];10(3):e0118800. Available from: https://journals.plos.org/plosone/article?id=10.1371/journal.pone.0118800

33. Klayman DL (1993) Artemisia annua: from weed to respectable antimalarial plant. ACS Symp. Ser. USA [Internet]. [cited 2021 Oct 18]; Available from: https://scholar.google.com/scholar_lookup?

title=Artemisia+annua\%3A+from+weed+to+respectable+antimalarial+plant\&author=Klayman\%2C+D.L.\&publication_year=1993

34. Klayman DL, Lin AJ, Acton N, Scovill JP, Hoch JM, Milhous WK et al (1984 Aug) Isolation of artemisinin (qinghaosu) from Artemisia annua growing in the United States. J Nat Prod 47(4):715-7

35. Lopes-Lutz D, Alviano DS, Alviano CS, Kolodziejczyk PP Screening of chemical composition, antimicrobial and antioxidant activities of Artemisia essential oils. Phytochemistry [Internet]. 2008a May 1 [cited 2020 Dec 30];69(8):1732-8. Available from:

http://www.sciencedirect.com/science/article/pii/S0031942208001076

36. Lopes-Lutz D, Alviano DS, Alviano CS, Kolodziejczyk PP Screening of chemical composition, antimicrobial and antioxidant activities of Artemisia essential oils. Phytochemistry [Internet]. 2008b May 1 [cited 2019 Nov 20];69(8):1732-8. Available from: http://www.sciencedirect.com/science/article/pii/S0031942208001076

37. Ma C, Wang H, Lu X, Li H, Liu B, Xu G Analysis of Artemisia annua L. volatile oil by comprehensive two-dimensional gas chromatography time-of-flight mass spectrometry. J. Chromatogr. A [Internet]. 2007 May [cited 2021 Oct 19];1150(1-2):50-3. Available from:

https://linkinghub.elsevier.com/retrieve/pii/S0021967306016694

38. Malik MM, Mujtaba Naqvi SH (1984) Screening of some indigenous plants as repellents or antifeedants for stored grain insects. J. Stored Prod. Res. UK [Internet]. [cited 2021 Oct 19]; Available from: https://scholar.google.com/scholar_lookup?

title=Screening+of+some+indigenous+plants+as+repellents+or+antifeedants+for+stored+grain+insects\&author=Malik\%2C+M.M.\&publication_year=1984

39. Mannan A, Ahmed I, Arshad W, Asim MF, Qureshi RA, Hussain I et al Survey of artemisinin production by diverse Artemisia species in northern Pakistan.Malar. J. 2010 Nov4;9:310

40. Margueritte L, Markov P, Chiron L, Starck J-P, Vonthron-Sénécheau C, Bourjot M et al Automatic differential analysis of NMR experiments in complex samples. Magn. Reson. Chem. [Internet]. 2018 [cited 2021 Oct 18];56(6):469-79. Available from: https://onlinelibrary.wiley.com/doi/abs/10.1002/mrc.4683

Page 10/17 
41. Nibret E, Wink M (2010a Apr) Volatile components of four Ethiopian Artemisia species extracts and their in vitro antitrypanosomal and cytotoxic activities. Phytomedicine Int J Phytother Phytopharm 17(5):369-374

42. Padalia RC, Verma RS, Chauhan A, Chanotiya CS, Yadav A (2011 Feb) Variation in the volatile constituents of Artemisia annua var. CIM-Arogya during plant ontogeny. Nat Prod Commun 6(2):239-242

43. Prior RL, Cao G, Prior RL, Cao G (2000 Aug) Analysis of botanicals and dietary supplements for antioxidant capacity: a review. J AOAC Int 83(4):950-6

44. Rana V, Blázquez M, Maiti S (2013 Jan) Essential oil composition of Artemisia annua L. at different growth stages. J Spices Aromat Crops 1:22:181-7

45. Segal R (1985) Sesquiterpene lactones from Artemisia herba alba,. Phytochemistry [Internet]. [cited 2021 Oct 19];24(6):1381-2. Available from:

https://linkinghub.elsevier.com/retrieve/pii/S0031942200811401

46. Sixt M, Strube J Systematic and Model-Assisted Evaluation of Solvent Based- or Pressurized Hot Water Extraction for the Extraction of Artemisinin from Artemisia annua L. Processes [Internet]. Multidisciplinary Digital Publishing Institute; 2017 Dec [cited 2021 Oct 18];5(4):86. Available from:

https://www.mdpi.com/2227-9717/5/4/86

47. Sylvestre M, Pichette A, Longtin A, Nagau F, Legault J (2006 Jan) Essential oil analysis and anticancer activity of leaf essential oil of Croton flavens L. from Guadeloupe. J Ethnopharmacol 3(1):99-102

48. Sz A, Hussain K, Hussain Z, Ali R, Abbas T (2016) Anti-Bacterial Activity of Different Soaps Available in Local Market of Rawalpindi (Pakistan) against Daily Encountered Bacteria.

49. Taramelli D, Monti D, Basilico N, Parapini S, Omodeo-Salé F, Olliaro P (1999 Sep) A fine balance between oxidised and reduced haem controls the survival of intraerythrocytic plasmodia. Parassitologia 41(1-3):205-208

50. Tzeng T, Lin Y, Jong T, Chang C Ethanol modified supercritical fluids extraction of scopoletin and artemisinin from Artemisia annua L. Sep. Purif. Technol. [Internet]. 2007 Aug 1 [cited 2021 Oct 18];56(1):18-24. Available from: https://linkinghub.elsevier.com/retrieve/pii/S1383586607000482

51. Patil V, Dass GK, Chandra S (2011) R. Artemisia afra and Modern Diseases. J. Pharmacogenomics Pharmacoproteomics [Internet]. [cited 2019 Nov 20];02(03). Available from: https://www.omicsonline.org/artemisia-afra-and-modern-diseases-2153-0645.1000105.php?aid=2815

52. Van Wyk B-E (2011) The potential of South African plants in the development of new medicinal products. South Afr. J. Bot. [Internet]. Oct 1 [cited 2019 Jul 3];77(4):812-29. Available from: http://www.sciencedirect.com/science/article/pii/S0254629911001190

53. Watt JM, Breyer-Brandwijk MG (1962) The medicinal and poisonous plants of Southern and Eastern Africa [Internet]. Edinburgh (United Kingdom) Livingstone; Available from: https://scholar.google.com/scholar_lookup? title=The+medicinal+and+poisonous+plants+of+Southern+and+Eastern+Africa\&author=Watt\%2C+J.M.\&publication_year=1962

54. Willcox M (2009 Feb) Artemisia species: From traditional medicines to modern antimalarials-and back again. J Altern Complement Med N Y N 15(2):101-109

55. World Health Organization. Programme on Traditional Medicine. WHO traditional medicine strategy 2002-2005 [Internet]. World Health Organization (2002) ; Report No.: WHO/EDM/TRM/2002.1. Available from: https://apps.who.int/iris/handle/10665/67163

56. Yineger H, Kelbessa E, Bekele T, Lulekal E Ethnoveterinary medicinal plants at Bale Mountains National Park, Ethiopia. J. Ethnopharmacol. [Internet]. 2007a May 30 [cited 2020 Dec 22];112(1):55-70. Available from: http://www.sciencedirect.com/science/article/pii/S0378874107000669

57. The World Medicines Situation 2011 - Traditional Medicines: Global Situation, Issues and Challenges [Internet]. [cited 2021a Oct 18]. Available from: http://digicollection.org/hss/en/m/abstract/Js18063en/

58. WHO traditional medicine strategy: 2014-2023 [Internet]. [cited 2021b Oct 18]. Available from: https://www.who.int/publications-detailredirect/9789241506096

\section{Tables}

Table 1: Fractionation of hexane/Ethyl acetate leaves for extract of Artimisia abyssinica

\begin{tabular}{|lll|}
\hline Fraction & Solvent systems & Amount (g) \\
\hline 1 & n-hexane & 0.4 \\
\hline 2 & n-hexane & 0.3 \\
\hline 3 & n-hexane/EtOAc (9:1) & 0.1 \\
\hline 4 & n-hexane/EtOAc (9:1) & 0.025 \\
\hline 5 & n-hexane/EtOAc (8:2) & 0.04 \\
\hline 6 & EtOAc & 0.1 \\
\hline
\end{tabular}

Table 2. ${ }^{1} \mathrm{H}$ and ${ }^{13} \mathrm{C}$ NMR spectral data of compounds AANH-1 and standard artemisinin 


\begin{tabular}{|c|c|c|c|c|}
\hline \multirow[t]{2}{*}{$\mathrm{C} / \mathrm{H}$} & \multicolumn{2}{|c|}{ AANH-1* } & \multicolumn{2}{|c|}{ Artemisinin** } \\
\hline & $\delta_{C}$ & $\delta_{H}($ multi., J, Hz) & $\delta_{C}$ & $\delta_{H}($ multi., J, Hz) \\
\hline 3 & 105.4 & & 106.7 & \\
\hline 4 & 35.9 & $3.43(\mathrm{~m})$ & 36.6 & $2.08(\mathrm{ddd})$ \\
\hline \multirow[t]{2}{*}{5} & 24.8 & $2.52(\mathrm{~m})$ & 25.7 & $2.01(\mathrm{~m})$ \\
\hline & & & & $1.47(\mathrm{~m})$ \\
\hline $5 a$ & 50.2 & $1.97(\mathrm{~m})$ & 51.2 & $1.38(\mathrm{~m})$ \\
\hline 6 & 37.6 & $2.47(\mathrm{~m})$ & 38.1 & $1.52(\mathrm{~m})$ \\
\hline \multirow[t]{2}{*}{7} & 32.9 & $1.76(\mathrm{~m})$ & 34.6 & $1.09(\mathrm{~m})$ \\
\hline & & $2.47(\mathrm{~m})$ & & $1.77(\mathrm{~m})$ \\
\hline 8 & 24.8 & $1.48(\mathrm{~m})$ & 24.0 & $1.17(\mathrm{~m})$ \\
\hline $8 a$ & 45.0 & $2.47(\mathrm{~m})$ & 45.6 & $1.82(\mathrm{~m})$ \\
\hline 9 & 33.6 & $3.60(\mathrm{~m})$ & 34.0 & $3.31(\mathrm{dq})$ \\
\hline 10 & 172.1 & & & \\
\hline 12 & 93.7 & $5.88(s)$ & 95.5 & $6.03(\mathrm{dq})$ \\
\hline $12 a$ & 79.5 & & 81.0 & \\
\hline 13 & 12.6 & $1.22(\mathrm{~d}, \mathrm{~J}=7.34)$ & 12.7 & $1.16(\mathrm{~d}, \mathrm{~J}=7.2)$ \\
\hline 14 & 19.8 & $1.02(\mathrm{~d}, \mathrm{~J}=5.36)$ & 19.9 & $0.99(\mathrm{~d}, \mathrm{~J}=6.2)$ \\
\hline 15 & 25.2 & $1.60(\mathrm{~s})$ & 25.2 & $1.38(\mathrm{~s})$ \\
\hline
\end{tabular}

* $\delta$ values are in ppm. ${ }^{1} \mathrm{H}: 400 \mathrm{MHz} ;{ }^{13} \mathrm{C}: 100 \mathrm{MHz}$; solvent and internal reference: $\mathrm{CDCl}_{3}$; multi: multiplicity ** (Margueritte et al. 2018) in $\left.\mathrm{CD}_{3} \mathrm{OD}, 700 \mathrm{MHz}\right)$

Table 3. ${ }^{1} \mathrm{H}$ and ${ }^{13} \mathrm{C}$ NMR spectral data of compounds AAN-7

\begin{tabular}{lllll} 
C/H & AAN-7 & & \multicolumn{2}{l}{ Dibydro-epideoxyartannrrin $B^{*}$} \\
\hline & $\delta_{\mathrm{C}}$ & $\delta_{\mathrm{H}}($ multi., J, Hz) & $\delta_{\mathrm{C}}$ & $\delta_{\mathrm{H}}$ (multi., J, Hz) \\
\hline 1 & 42.8 & $2.16(\mathrm{~m})$ & 42.9 & \\
\hline 2 & 23.7 & $1.93(\mathrm{~m})$ & 23.8 & \\
\hline 3 & 31.9 & $1.47(\mathrm{~m})$ & 32.4 & \\
\hline 4 & 142.3 & & 142.5 & \\
\hline 5 & 121.8 & $5.65(\mathrm{~s})$ & 121.8 & $5.63(\mathrm{~s})$ \\
\hline 6 & 83.2 & & 83.4 & \\
\hline 7 & 39.6 & $2.19(\mathrm{~m})$ & 39.7 & \\
\hline 8 & 21.0 & $2.13(\mathrm{~m})$ & 21.0 & \\
\hline 9 & 30.6 & $1.30(\mathrm{~m})$ & 30.8 & \\
\hline 10 & 32.4 & $1.23(\mathrm{~m})$ & 32.7 & \\
\hline 11 & 46.5 & $3.13(\mathrm{~m})$ & 46.6 & $3.15(\mathrm{dq} . \mathrm{J} 1=7.0, \mathrm{~J} 2=7.2)$ \\
\hline 12 & 179.5 & & 179.5 & \\
\hline 13 & 9.4 & $1.24(\mathrm{~d}, \mathrm{~J}=7.1)$ & 9.4 & $1.15(\mathrm{~d}, \mathrm{~J}=7.2)$ \\
\hline 14 & 19.8 & $0.93(\mathrm{~d}, \mathrm{~J}=6.6)$ & 19.6 & $0.93(\mathrm{~d}, \mathrm{~J}=6.6)$ \\
\hline 15 & 23.4 & $1.71(\mathrm{~s})$ & 23.5 & $1.75(\mathrm{~s})$ \\
\hline
\end{tabular}

$\delta$ values are in ppm. ${ }^{1} \mathrm{H}: 400 \mathrm{MHz} ;{ }^{13} \mathrm{C}: 100 \mathrm{MHz}$; solvent and internal reference: $\mathrm{CDCl}_{3}$; multi: multiplicity, *(Brown 1992).

Table 4: Antimicrobial sensitive test (Zone of inhibition in mm diameter) for Artemisia annua and Artemisia absinthium 


\begin{tabular}{|c|c|c|c|c|c|c|c|c|c|c|c|c|}
\hline Test strains & \multicolumn{3}{|c|}{ Zone of inhibition(mm) for Plant extract } & \multicolumn{9}{|c|}{ Positive control $(\mathrm{IZ}=\mathrm{mm}$} \\
\hline Hospital acquired A. baumannii & 34 & 15 & 35 & 21 & 16 & no & no & - & - & - & - & no \\
\hline E. Coli ATCC $25922^{\top}$ & 19.67 & 12 & 15.67 & 24 & 35 & - & 21 & 23 & 22 & - & - & - \\
\hline Klebsiella pneumoniae ATCC $1053^{\top}$ & 3 & $<3$ & 5 & 25 & 30 & - & 23 & - & 27 & - & - & - \\
\hline Shigella boydii ATCC1233 ${ }^{\top}$ & no & no & no & 35 & 40 & - & 25 & 27 & 27 & - & - & - \\
\hline 19. aureus ATCC $25923^{\top}$ & 12.67 & 17.5 & 20.33 & - & - & 24 & - & 20 & 20 & 25 & 25 & 40 \\
\hline
\end{tabular}

Note: A.ah- Artemisia annua $n$-hexane extract, A.ap - Artemisia annua petroleum ether extract and A. abe-

Artemisia absinthium ethyl acetate extract

Table 5: Zone of inhibition against some strains of bacteria by test extract of Artemisia abyssinica at different concentrations.

\begin{tabular}{|c|c|c|c|c|c|c|c|c|c|c|c|c|c|}
\hline \multirow[t]{2}{*}{ Test extract } & \multirow[t]{2}{*}{$\begin{array}{l}\text { Conc. } \\
(\mathrm{mg} / \mathrm{ml})\end{array}$} & \multicolumn{2}{|c|}{ A. baumannii } & \multicolumn{2}{|c|}{$\begin{array}{l}\text { E. coli } \\
\text { ATCC } 25922^{\top}\end{array}$} & \multicolumn{2}{|c|}{ K. pneumonia ATCC1053 ${ }^{\top}$} & \multicolumn{2}{|c|}{$\begin{array}{l}\text { S. enteritidis } \\
{\text { ATCC } 13076^{\top}}^{\top}\end{array}$} & \multicolumn{2}{|c|}{$\begin{array}{l}\text { Shigella boydii } \\
\text { ATCC1233 }^{\top}\end{array}$} & \multicolumn{2}{|c|}{$\begin{array}{l}\text { S. aureus } \\
\text { ATCC } 25923^{\top}\end{array}$} \\
\hline & & $\mathrm{IV} / \mathrm{IZ}$ mm & $S$ & IV/IZ mm & $S$ & $\mathrm{IV} / \mathrm{IZ}$ (mm) & $S$ & IV/IZ (mm) & $S$ & IV/IZ (mm) & $\mathrm{S}$ & IV/IZ (mm) & $S$ \\
\hline A. $a_{h}$ & 0.11 & $14 / 34$ & $S$ & $6.84 / 19.67$ & $S$ & 3 & M & $5.5 / 17$ & M & no & - & $3.34 / 12.67$ & M \\
\hline A. $a_{p}$ & 0.11 & $4.5 / 15$ & M & $3 / 12$ & $\mathrm{M}$ & $<3$ & M & $6 / 18$ & M & no & - & $5.75 / 17.5$ & M \\
\hline A. $a b_{e}$ & 0.03 & $14.5 / 35$ & $S$ & $4.84 / 15.67$ & $M$ & 5 & $M$ & $7 / 20$ & $M$ & no & - & $7.17 / 20.33$ & $S$ \\
\hline
\end{tabular}

Key: A.ach - For test extract of Artemisia abyssinica (also known as "chikugn" or "Ajo" in Ethiopia). F - is for fractionated test extract of Artemisia abyssinica, S is for sensitivity, IZ- for inhibition zone, IV - is for Inhibition Value. S=sensitive, R=Resistance Antibiotics used for QC: Ceftraxone and Ceftazidime, $\mathrm{M}$ - for moderately shown inhibition zone

Table 6: Zone of inhibition against some strains of bacteria by test extract of Artemisia abyssinica at different concentration and fractionation

\begin{tabular}{|c|c|c|c|c|c|c|c|c|c|}
\hline \multirow[t]{2}{*}{$\begin{array}{l}\text { Sample } \\
\text { (A.ach) }\end{array}$} & \multirow[t]{2}{*}{ Conc. $(\mathrm{mg} / \mathrm{ml})$} & \multicolumn{2}{|c|}{$\begin{array}{l}\text { S. aureus } \\
\text { ATCC } 25923^{\top}\end{array}$} & \multicolumn{2}{|c|}{ S. pyogen ATCC 19615} & \multicolumn{2}{|c|}{ E. coli ATCC $25922^{\top}$} & \multicolumn{2}{|c|}{ S. typhimurium } \\
\hline & & IZ (mm) & Sensitivity & IZ (mm) & Sensitivity & IZ (mm) & Sensitivity & IZ (mm) & Sensitivity \\
\hline A. $a c_{h}$ F3 & 0.6 & 12 & $\mathrm{~S}$ & 12 & $\mathrm{~S}$ & 12 & $\mathrm{~S}$ & 15 & S \\
\hline A. $a c_{h} F 4$ & 1.30 & 20 & $S$ & 25 & $S$ & 15 & $S$ & 17 & $S$ \\
\hline A. $a c_{h}$ F5 & 0.10 & 11 & $S$ & 14 & $S$ & 9 & $S$ & 10 & $S$ \\
\hline $\begin{array}{l}\text { A. } a c_{h} \text { or } \\
\text { EtOAc (8: }\end{array}$ & 0.20 & 10 & $S$ & 11 & $S$ & 13 & $S$ & 8 & $S$ \\
\hline A.ac oil & 0.08 & 10 & $S$ & 12 & $S$ & 20 & $S$ & 8 & S \\
\hline
\end{tabular}

Key: A.ach - For n-hexane extract of Artemisia abyssinica (also known as "chikugn" or "Ajo" in Ethiopia). F indicate for fractionated test extract of Artemisia abyssinica; $\mathrm{S}$ is for sensitivity, IZ - is for Inhibition zone, R for Resistance. QC is for Ceftraxone and Ceftazidim

\section{Figures}



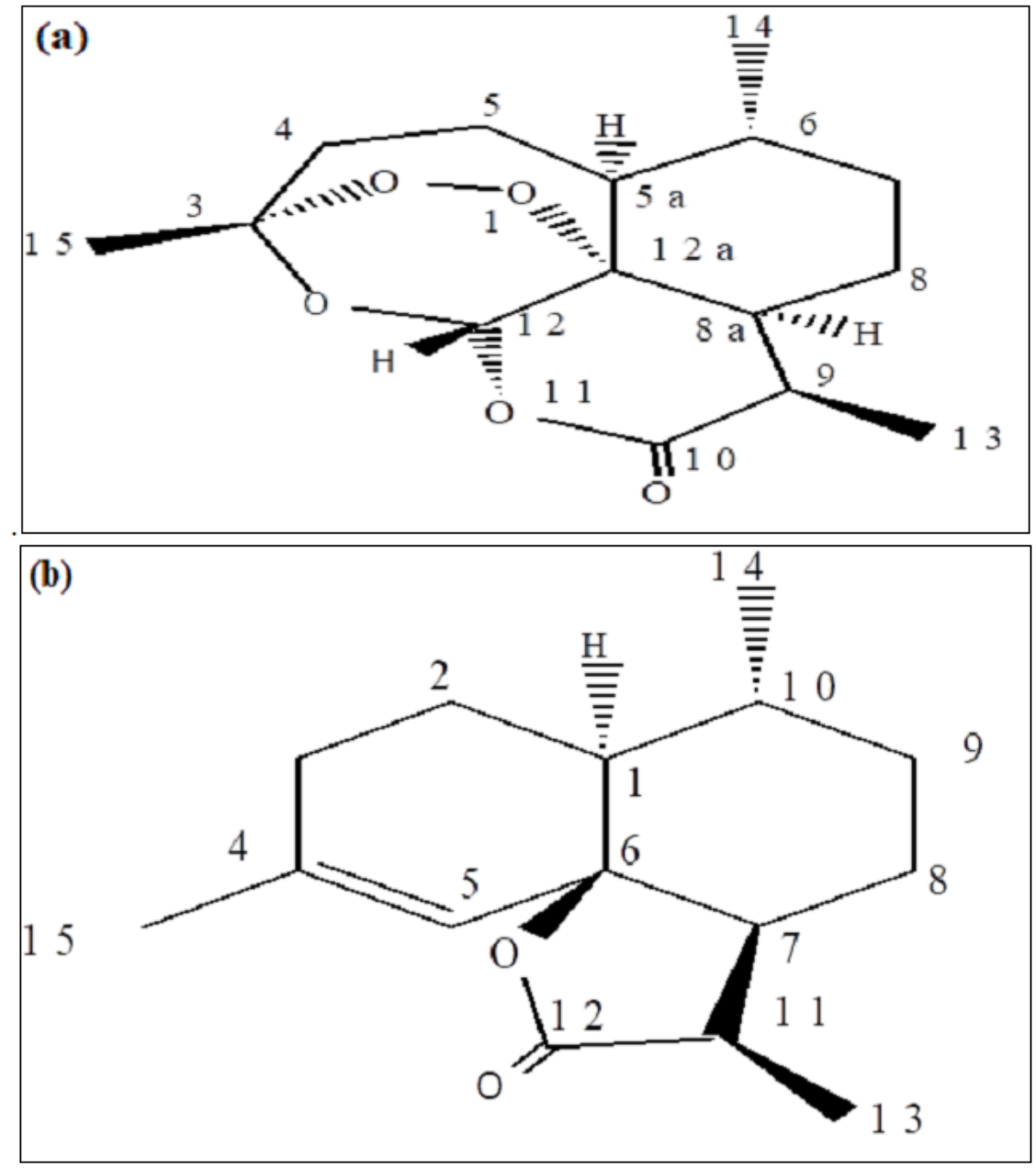

Figure 1

(a) Structure of artemisinin (b) Structure of AAN-7 

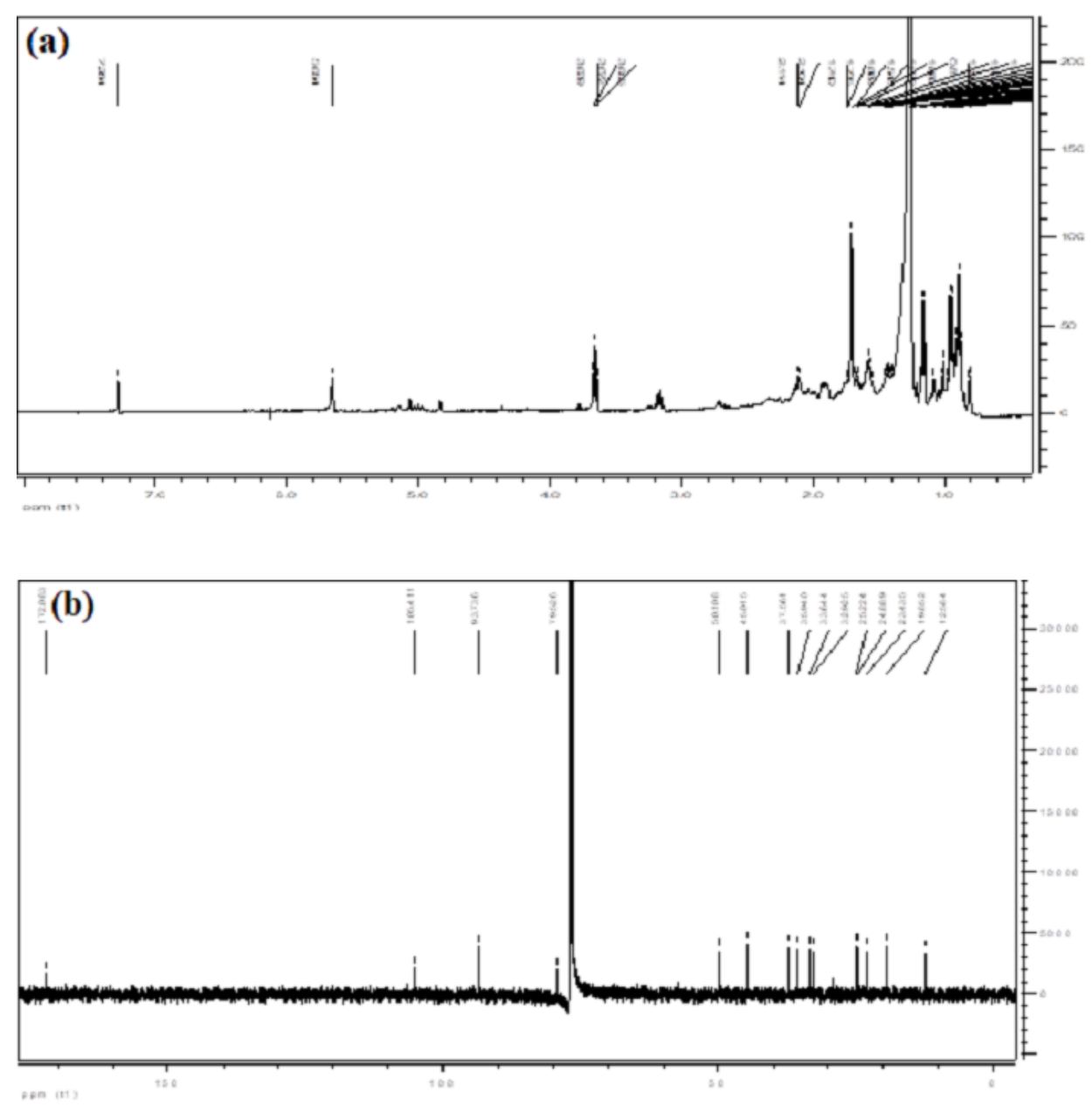

Figure 2

(a)1 H NMR spectrum of artemisinin (AANH-1). (b) 13C NMR spectrum of artemisinin (AANH-1) 


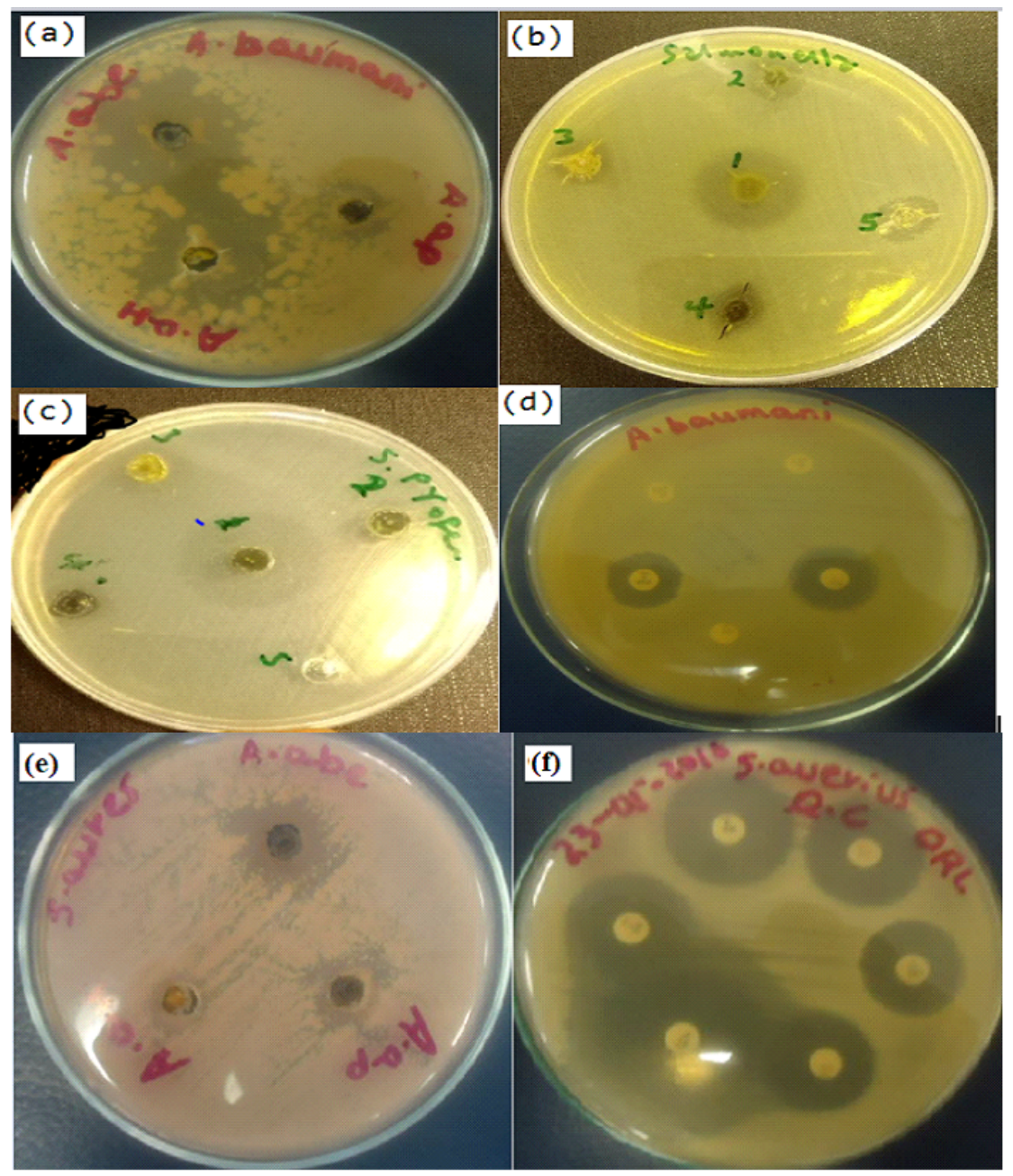

\section{Figure 3}

Zone of inhibition for Hospital acquired A. baumannii due to (a) plant extract of A.ah, A.ap and A.abe. (b) Zone of inhibition for Salmonella spp (c) Maximum zone of inhibition for S. pyogen ATCC 19615. (e) Zone of inhibition due to A. abe, A.ah, and A.ap against Staphylococcus aureus (f) Zone of Inhibition due to some Standard impregnated disks. 


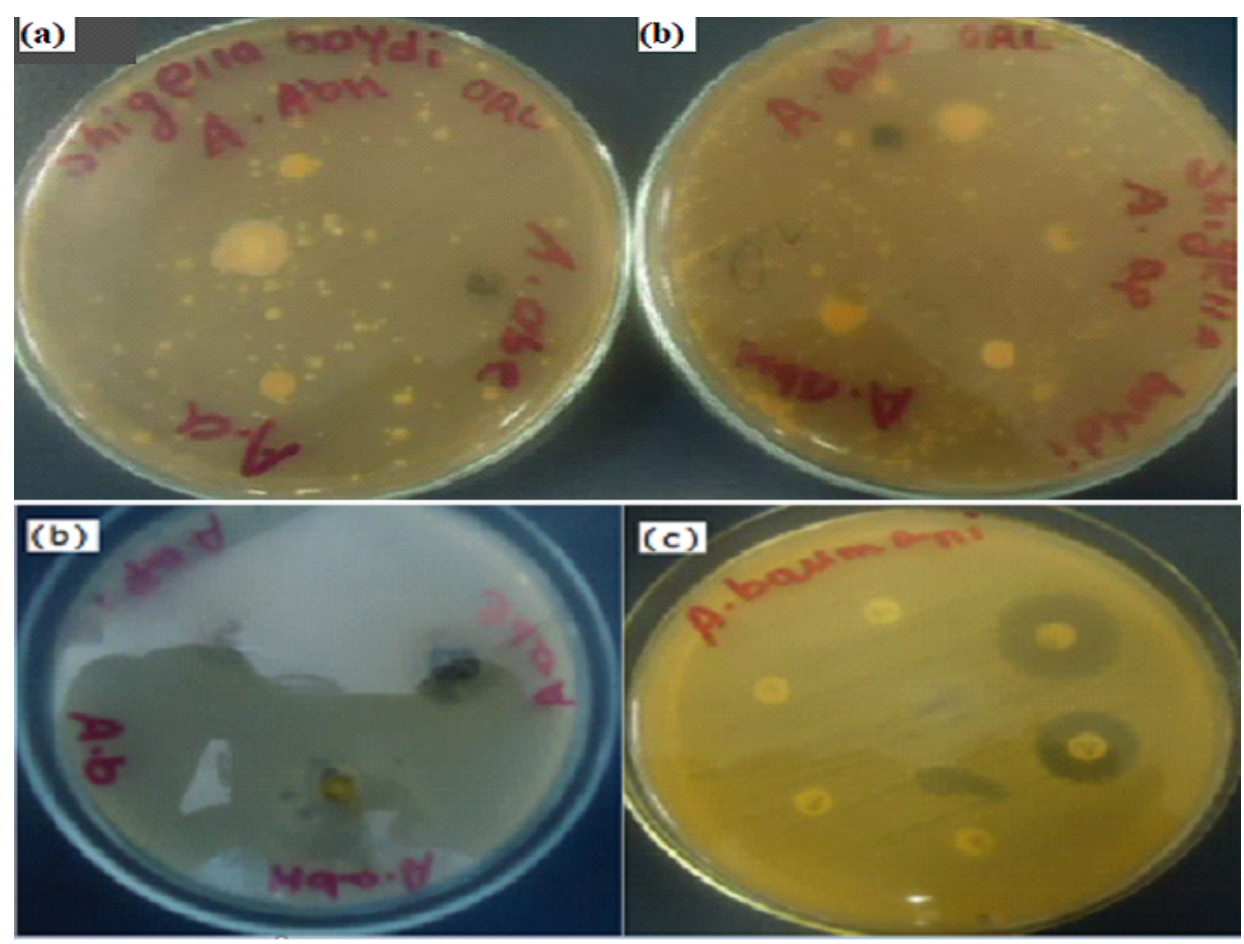

Figure 4

(a) No zone of inhibition was recorded for Shigella boydii ATCC 1233T (b) Synergistic effect of A.ah and A. abe on Hospital acquired A. baumannii (c). Zone of inhibition for some Standard impregnated disks. (d) Zone of inhibition against Shigella boydii by A.ap. extracts.

\section{Supplementary Files}

This is a list of supplementary files associated with this preprint. Click to download.

- supplementaryfile.docx 